See discussions, stats, and author profiles for this publication at: https://www.researchgate.net/publication/297753270

\title{
Accelerating access to new medicines: Current status of facilitated regulatory pathways used by emerging regulatory authorities
}

Article in Journal of Public Health Policy · March 2016

DOI: $10.1057 /$ jphp.2016.8

\section{CITATIONS}

10

9 authors, including:

Lawrence Liberti

Centre for Innovation in Regulatory Science

26 PUBLICATIONS 311 CITATIONS

SEE PROFILE

Neil Mcauslane

Centre for Innovation in Regulatory Science

65 PUBLICATIONS 429 CITATIONS

SEE PROFILE

Some of the authors of this publication are also working on these related projects:

Facilitated regulatory pathways in the emerging markets View project

Controlled Release and Physical Pharmacy View project
161

Jarno Hoekman

Utrecht University

54 PUBLICATIONS $\quad 1,677$ CITATIONS

SEE PROFILE

Kaining Zhi

The University of Tennessee Health Science Center

8 PUBLICATIONS 35 CITATIONS

SEE PROFILE 


\section{Original Article}

\section{Accelerating access to new medicines: Current status of facilitated regulatory pathways used by emerging regulatory authorities}

Lawrence Liberti $^{\mathrm{a}, \mathrm{b}, *}$, Alasdair Breckenridge ${ }^{\mathrm{c}}$, Jarno Hoekman ${ }^{\mathrm{b}, \mathrm{d}}$, Hubert Leufkens ${ }^{\mathrm{b}}$, Murray Lumpkin ${ }^{\mathrm{e}}$, Neil McAuslane ${ }^{\mathrm{a}}$, Pieter Stolk ${ }^{\mathrm{b}}$, Kaining Zhi $^{\mathrm{f}}$, and Lembit Rägo ${ }^{\mathrm{g}}$

${ }^{a}$ Centre for Innovation in Regulatory Science (CIRS), 77 Hatton Garden, London ECIN 8JS, UK

${ }^{b}$ Utrecht Institute for Pharmaceutical Sciences, Utrecht University 3584 CS Utrecht, The Netherlands

${ }^{c}$ School of Life Sciences, University of Liverpool, Liverpool L69 7ZB, UK

${ }^{\mathrm{d}}$ Innovation Studies Group, Copernicus Institute for Sustainable Development, Utrecht University 3584 CS Utrecht, The Netherlands

'The Bill and Melinda Gates Foundation, Seattle, WA 98 I09, USA

${ }^{\mathrm{f}}$ Temple University School of Pharmacy, Philadelphia, PA I9I40, USA

${ }^{\mathrm{g}}$ The World Health Organization, Geneva I 2 I I, Switzerland

*Corresponding author. E-mail: LLiberti@cirsci.org

Abstract Objectives: We assessed the characteristics of currently implemented expedited (facilitated) regulatory pathways (FRPs) used by national regulatory authorities (NRAs) in emerging economies to speed access to important new medicines. Methods: We identified NRAs with FRPs through Thomson Reuters Cortellis Regulatory Intelligence and through agency Websites. We developed a list of 27 FRP characteristics. We categorised characteristics as procedural or substantive and based them on five sequential regulatory activities. Findings: We assessed 29 countries with 33 FRPs. The regions with the characteristics described most extensively by their FRPs were the Middle East/North Africa and Eastern Europe. The SubSaharan African region included the FRPs that were least specific in describing characteristics. Overall, FRPs presented at least twice as many procedural as substantive characteristics. Conclusions: We observed diversity by region in FRP characteristics, suggesting a role for further engagement with emerging NRAs in their design and implementation. Common processes could advance regulatory alignment initiatives and help the WHO inform the development of novel, globally 
aligned accelerated development and regulatory pathways for products that fulfil serious unmet public health needs.

Journal of Public Health Policy advance online publication, Io March 2016; doi:I0.1057/jphp.20I6.8

Keywords: facilitated regulatory pathways (FRPs); emerging national regulatory authorities (emerging NRAs); regulatory characteristics; expedited access; regulatory alignment initiatives

\section{Introduction}

Important new medicines for serious diseases or for unmet medical needs have been introduced in the last 20 years. Novel approaches for HIV, malaria and cancers, plus recently Ebola, have highlighted the need for clear pathways for expedited regulatory reviews and approvals. ${ }^{\mathrm{I}}$ In response to the need to expedite the review of new therapies, national regulatory authorities (NRAs) have implemented, for products that address unmet serious public health needs, expedited review pathways to provide more rapid alternatives to standard processes. ${ }^{2}$

We characterise these expedited pathways as facilitated regulatory pathways (FRPs) for situations where there is an unmet medical need. They provide alternatives to standard product development and regulatory review routes. ${ }^{3}$ The goal of FRPs is to speed the development, marketing authorisation and patient access to new drugs with positive benefit-risk balances. FRPs may increase communication and commitment between the developer and the regulatory agency. The latter can give greater weight to surrogate endpoints, and may move some of the burden of generating clinical evidence of benefit and safety from the preto the post-authorisation phase.

FRPs are increasingly important to NRAs in low- and middle-income countries. We call them 'emerging NRAs'. Global initiatives support an expanding portfolio of products for neglected diseases ${ }^{4}$ now that emerging NRAs and the World Health Organization (WHO) are expanding their commitment to assure new treatments will be widely and readily available. Newly developed country-specific pathways expedite the regulatory review of new treatments for serious conditions, particularly where there is unmet medical need or where the therapy represents an important innovation.

Unlike FRPs being used or piloted by stringent regulatory authorities (SRAs), no one has systematically reviewed and assessed formal FRPs

3 I6 (C) 20I6 Macmillan Publishers Ltd. or97-5897 Journal of Public Health Policy Vol. 37, 3, 315-333 
implemented by emerging NRAs (SRAs are members of the International Conference for Harmonisation of Technical Requirements for Registration of Pharmaceuticals for Human Use [ICH]). ${ }^{5,6}$

To understand the diversity and similarities, we undertook this descriptive study of operating FRPs used by emerging NRAs. We wanted to help ongoing assessment and development of national regulatory systems; to help standardise approaches to accelerated medicine reviews; and to provide international organisations with evidence to help focus their regulatory strategies and increase capacity within emerging NRAs. Common FRP processes might inform and speed the development of novel, globally aligned, accelerated development and regulatory authorisation pathways.

\section{Methods}

We conducted this study between January 2015 and April 2015, starting with a list of emerging NRAs likely to have an FRP in place. The list was based on prior assessments of the regulatory capacity of emerging medicines regulatory systems ${ }^{7-9}$ and supplemented by a search of Cortellis Regulatory Intelligence (a Thomson Reuters database). We used Boolean combinations of the following search terms: priority, expedited, fast track, accelerated review/approval, neglected disease, unmet medical need.

We developed a list of 27 FRP characteristics (Table I) based on an assessment of characteristics of FRPs in SRAs, plus elements of FRPs identified by a perception survey. ${ }^{3}$ We added other characteristics based on our own experience. We used two groupings to determine the emphasis of characteristics.

- Were the characteristics 'procedural' (rules/activities related to overall process; I 8 characteristics) or 'substantive' (those used to determine how the evidence supports the outcome; 9 characteristics)?

- Where did they fit in the 5 sequential regulatory activities:

I. those describing ways for agencies to assist the sponsor to facilitate the submission or review ( 6 characteristics);

2. criteria for the acceptance of the regulatory dossier (9 characteristics);

3. review process attributes (4 characteristics);

4. decision criteria (4 characteristics);

5. post-authorisation and disengagement activities (4 characteristics). 


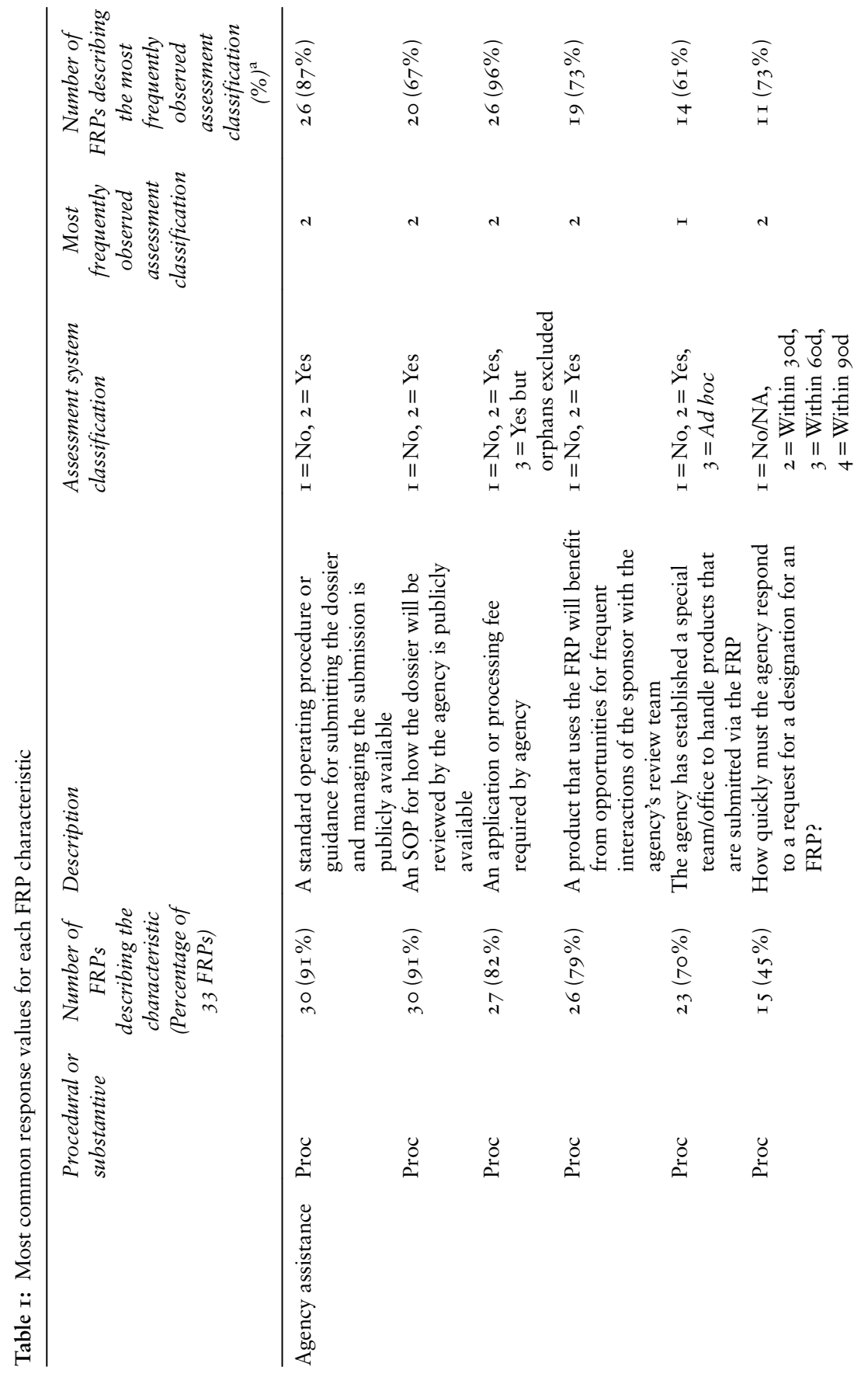




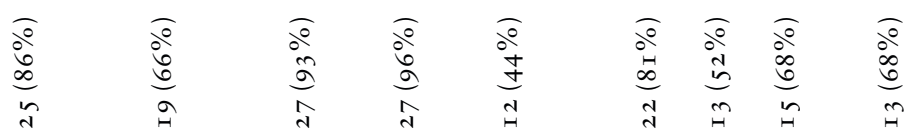
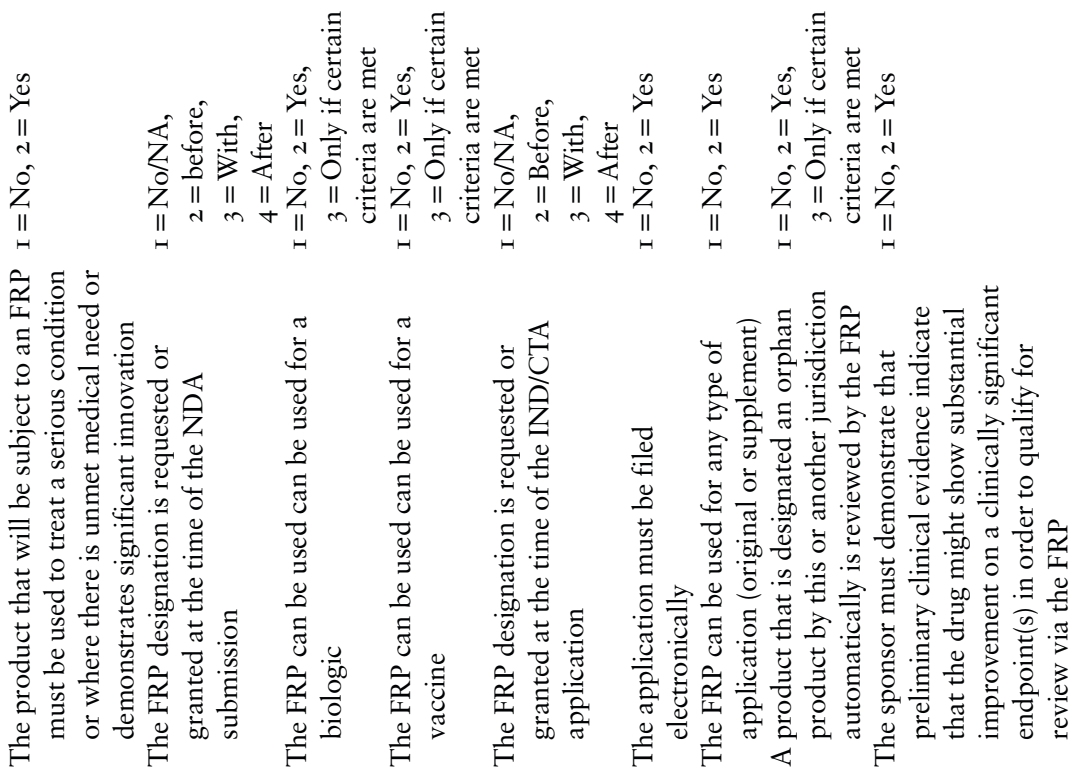

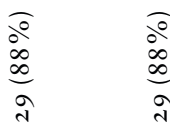

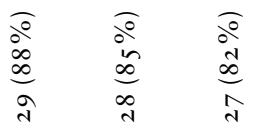

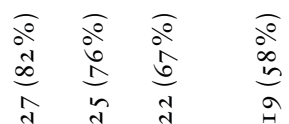

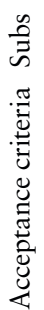

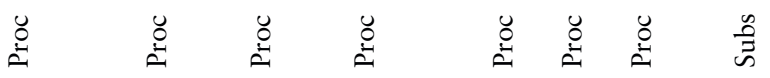

@ 


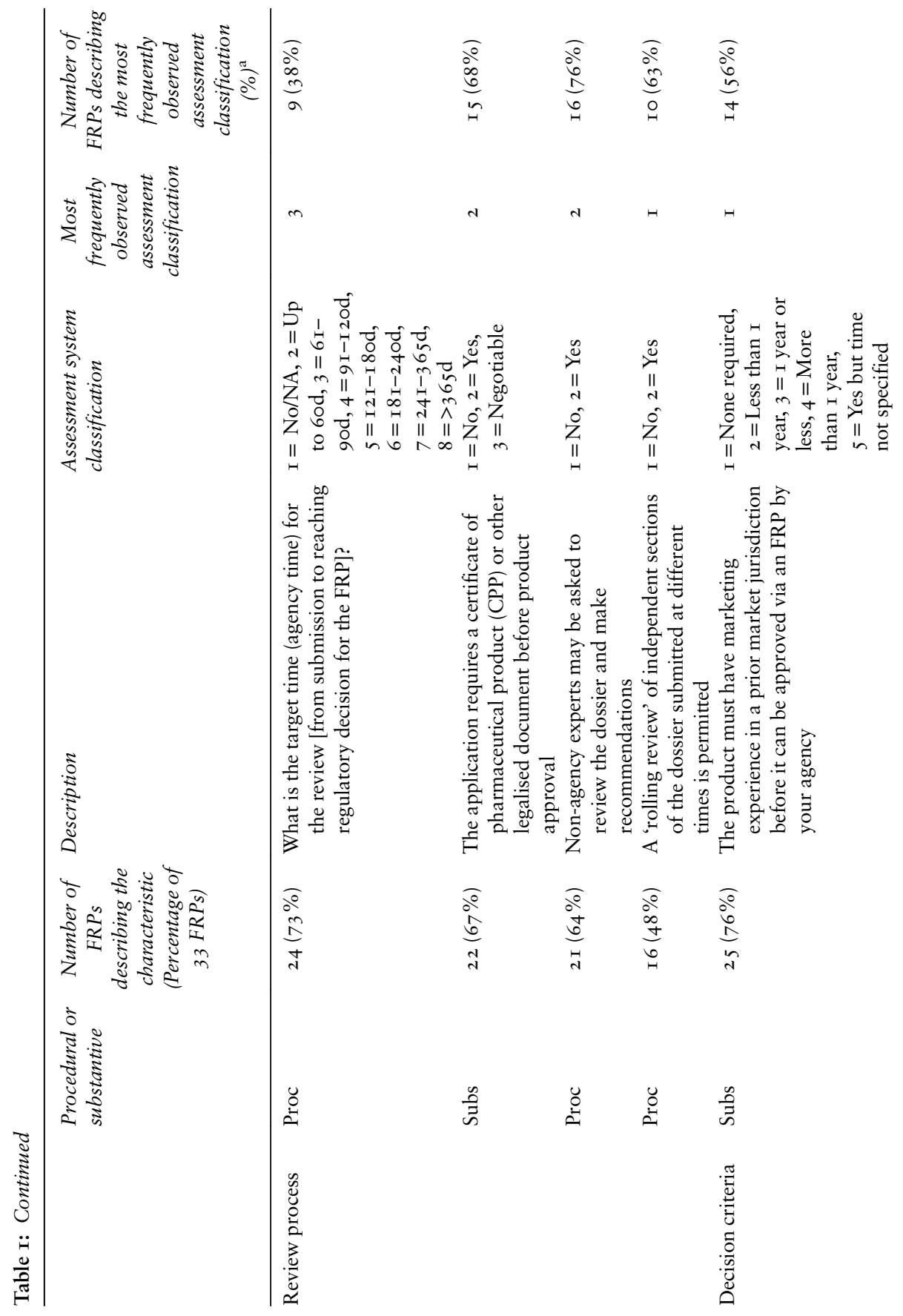




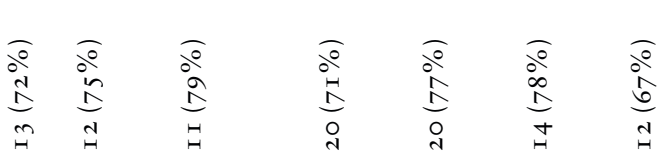

$$
\begin{aligned}
& h \quad h \quad 4 \quad m \quad 4 \quad \frac{4}{4}
\end{aligned}
$$
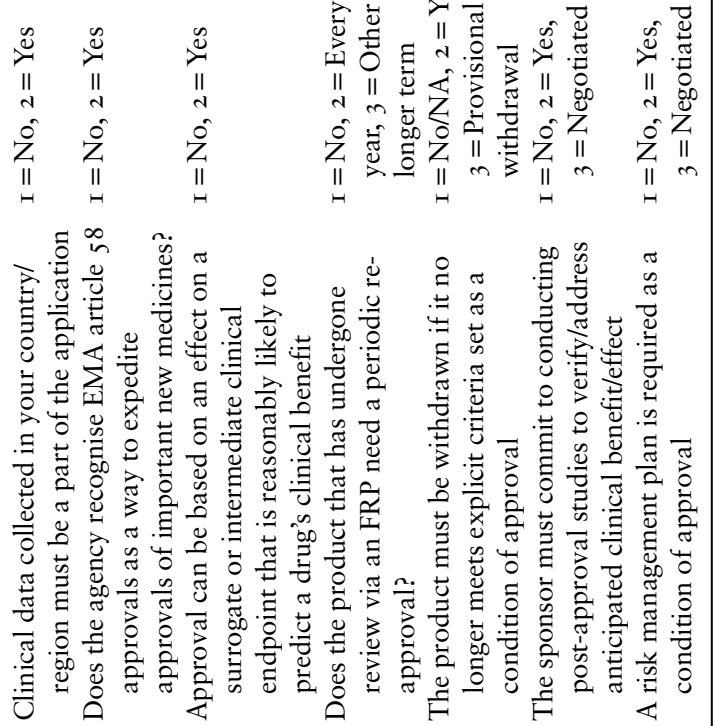

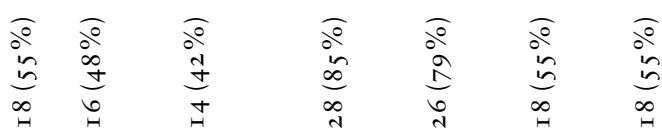

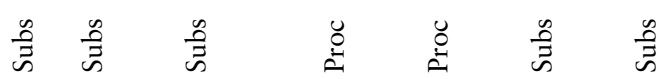

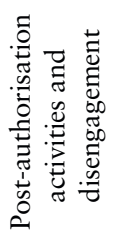

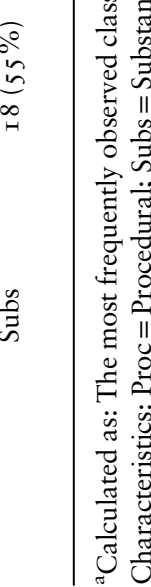


We developed an assessment methodology to enable consistent categorisation of each characteristic addressed by each FRP. Using a standard characteristic assessment form, we noted whether they were present or not (yes/no binary assessments) or placed them on an assessment scale (for example, ordinal). Two of the authors independently assessed each characteristic. (KZ conducted the first assessment, LL the second). They resolved interpretive disagreements through discussion.

To confirm our interpretation of the public information, we sent the characteristic assessment form for each country to contacts in the respective emerging NRAs to review our interpretations. If the NRA made changes, we asked the respondents to explain the change. When we did not receive a response from the NRA, we sent the assessment form to a local non-governmental regulatory expert for comment. If no comments were received, we used our initial findings. Thus characteristics for each FRP were those described in publicly available documents, modified by expert commentary. We received responses over 3 months.

For each characteristic, we compared the number of FRPs that addressed the characteristic with total FRPs in this cohort. We then identified the most frequently observed classification assessment for each characteristic. We calculated a frequency percentage using the number of FRPs that addressed the characteristic as the denominator. For each FRP, we compared the proportion of characteristics addressed per FRP. We calculated the frequency of procedural and substantive characteristics, with the median number of characteristics counted by geographic region. We expected that no emerging NRA would have addressed all 27 characteristics in its public documentation.

\section{Results}

We initially identified 67 countries that might have an FRP. With further searches, using Cortellis Regulatory Intelligence and publicly available Web-based resources (for example, agency Websites), we learned that $3 \mathrm{I}$ of these countries had no FRPs (false positives). Some of the remaining 36 had a form of FRP. We found only a cursory description for seven countries and excluded them from the analysis. Twenty-nine countries had publicly available information that described their FRPs. We received characteristics assessment forms from I7 countries describing I9 FRPs. From I 2 countries we received no input describing their I 4 FRPs. We therefore, assessed 33 FRPs from 29 countries.

322 (C) 20I6 Macmillan Publishers Ltd. or97-5897 Journal of Public Health Policy Vol. 37, 3, 315-333 


\section{Overall FRP characteristics}

Table I presents how often FRPs addressed a characteristic and the most common assessment for each characteristic. For each FRP, we summed and compared the number and distribution of characteristics addressed by country and region (Table 2 ).

The regions with the largest number of characteristics addressed by FRPs (median number) were Middle East/North Africa (I7) and Eastern Europe (I7). Sub-Saharan African FRPs addressed the fewest characteristics (9).

Consistent with the predominance of procedural characteristics in our scheme, all FRPs addressed at least twice as many procedural as substantive characteristics. The most commonly addressed procedural characteristics were 'having a standard operating procedure (SOP)' or 'having guidance for submitting the dossier' (30/33; 9I per cent) and 'an SOP on how the dossier will be reviewed' (30/33; 9I per cent). The most commonly addressed substantive characteristic was whether the product must be used to treat a serious condition or presence of an unmet medical need $(29 / 33$; 88 per cent). We summarise the most frequently observed characteristics (addressed by 70 per cent or more of the FRPs) in Figure I. Of these I 5 common characteristics, I I were procedural and 4 substantive.

We organised these characteristics by the five sequential regulatory activities. Percentages reflect the most frequently observed response as a proportion of the total number of responses for that characteristic.

\section{Enabling assistance to facilitate the submission or review}

Most FRPs offered a way for regulators to provide pre-submission assistance to sponsors (Table I). SOPs or guidelines for submission and about the review process usually informed sponsors. A majority (I9/26; 73 per cent) of FRPs provided opportunities for frequent interaction between the sponsor and the agency's review team. Most (I4/23; 6I per cent) did not specify the establishment of a special team or office to manage submissions via the FRP. Processing fees varied widely, from less than US\$ Ioo० to many times the standard submission processing fee.

Criteria for the acceptance of the regulatory dossier While most $(25 / 29 ; 86$ per cent) FRPs focused on products for serious diseases or for unmet medical needs, many ( $15 / 22 ; 68$ per cent) did not automatically consider orphan products to be candidates for FRP review.

(C) 2016 Macmillan Publishers Ltd. oI97-5897 Journal of Public Health Policy Vol. 37, 3, 3I5-333 323 


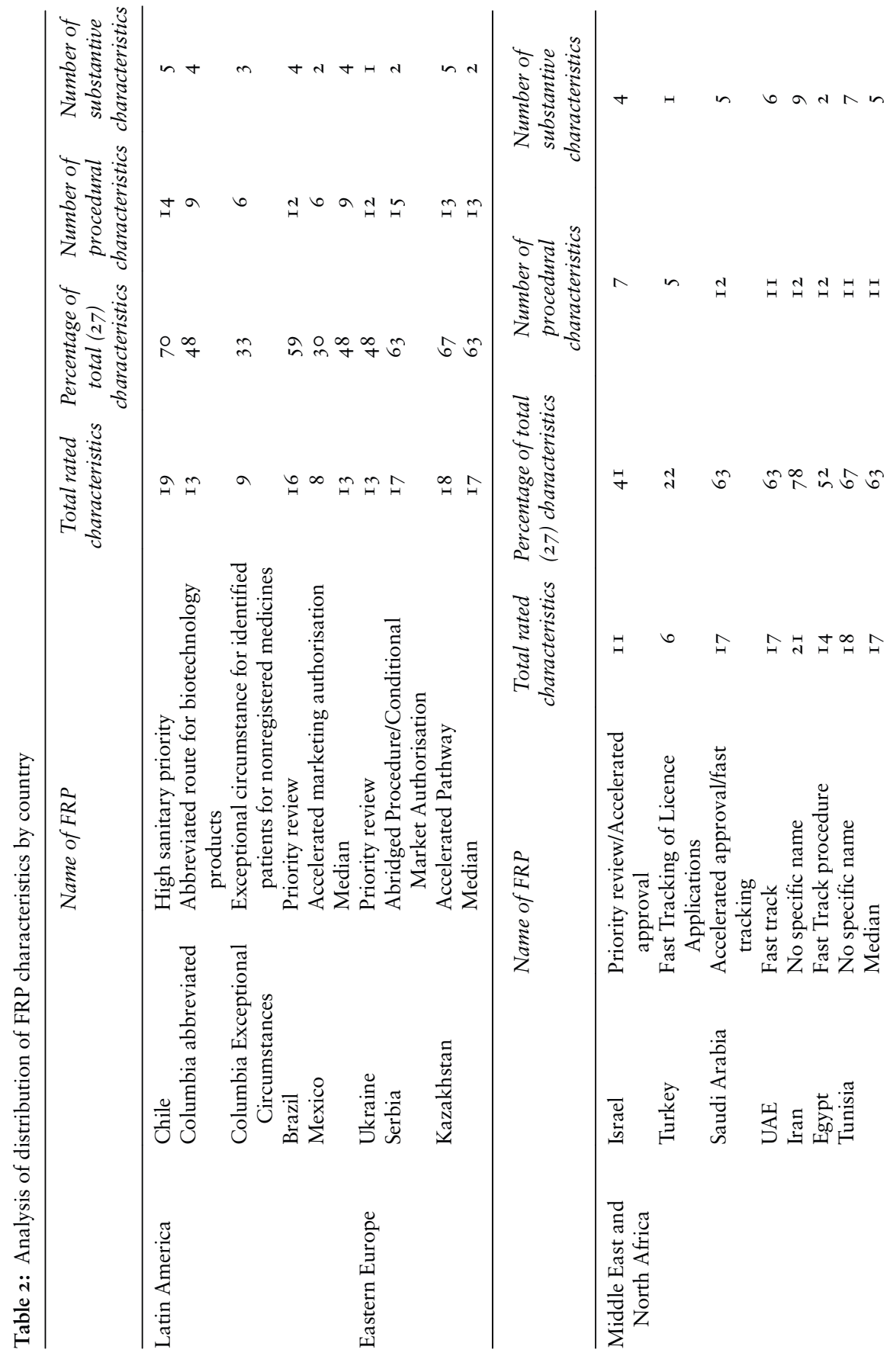




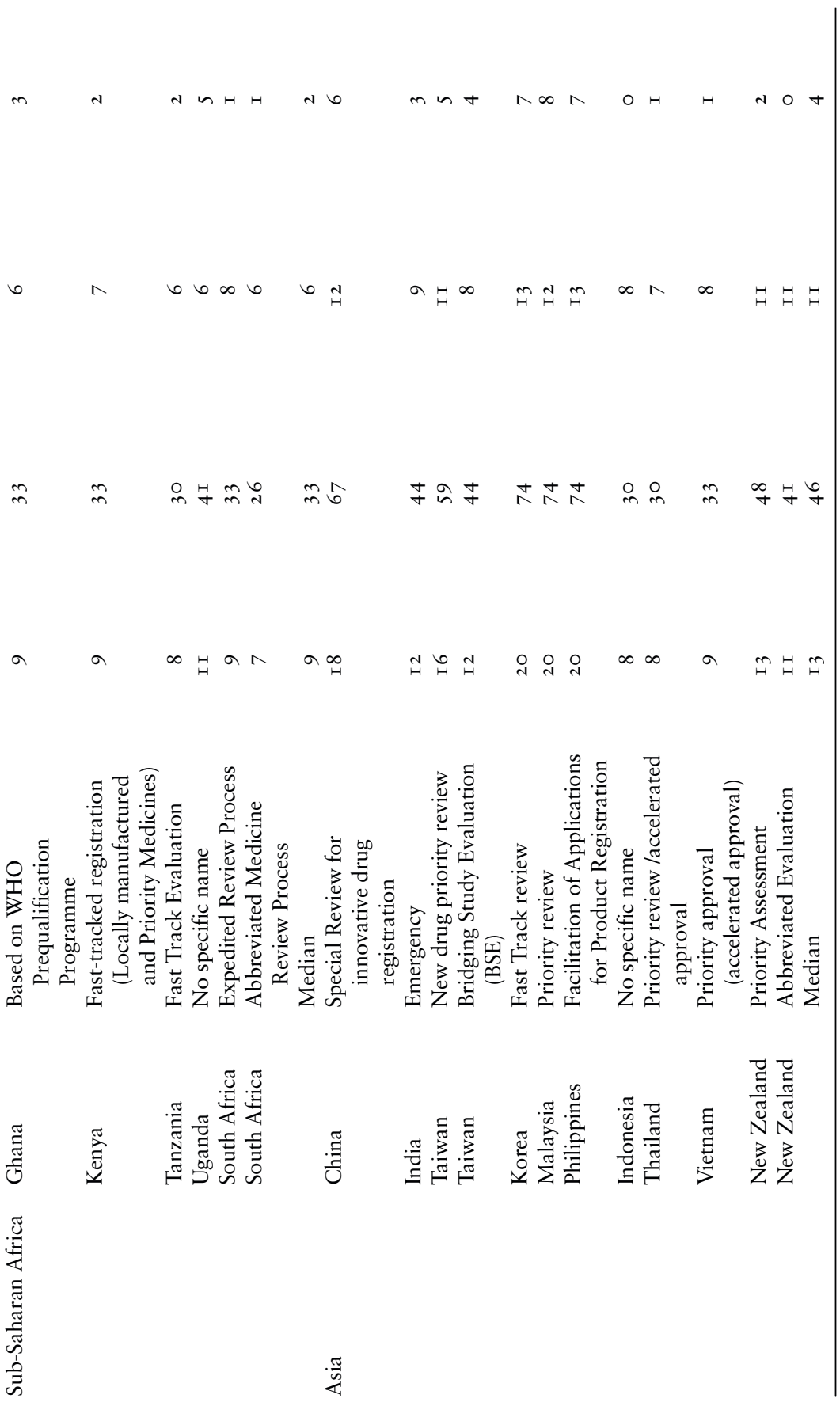



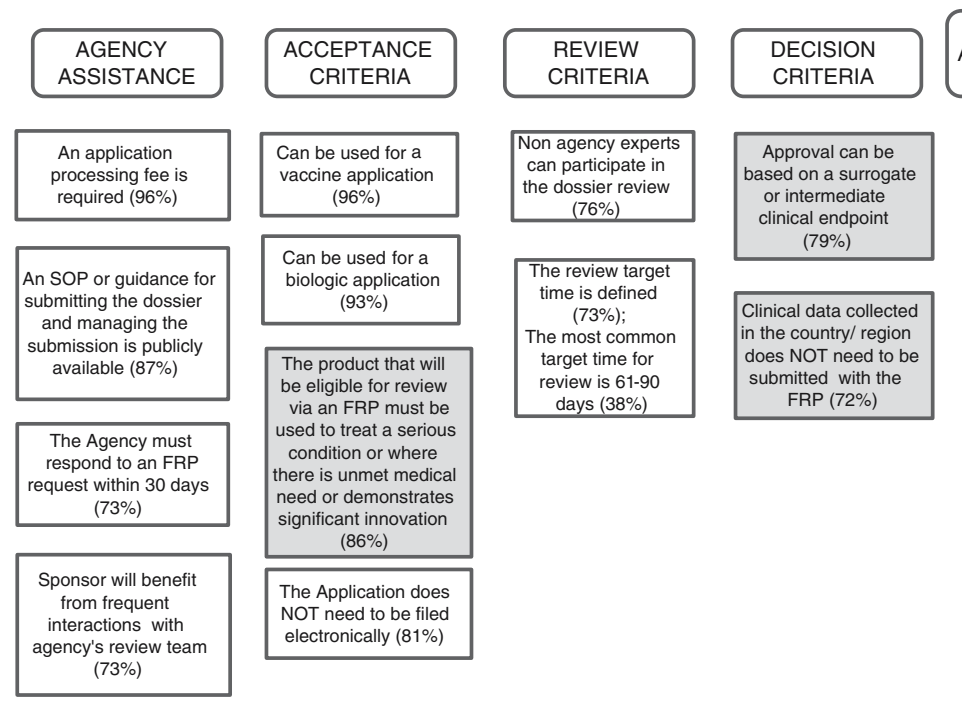

POST -

AUTHORISATION

ACTIVITIES

Figure I: Common facilitating practices observed in facilitated regulatory pathways.

Note: Percentages were calculated by dividing the most frequently observed response by the number of FRPs for which that characteristic could be assessed. Substantive characteristics are shaded.

Most FRPs (>93 per cent) applied whether or not the product was a drug, biologic, or vaccine. They also applied for both initial and follow-on supplemental marketing authorisation applications ( $\mathrm{I}_{3} / 25$; 52 per cent). FRPs typically ( $19 / 29 ; 66$ per cent) asked that a request for an expedited designation be made when an application for marketing was submitted. For SRAs, a request to use an FRP may occur at any time during development. ${ }^{\text {IO }}$

\section{Review process attributes}

Of the 24 FRPs for which a review target period was defined, all but one had a target of I 80 days or less. Thirteen ( 54 per cent) had a target of 90 days or less. Fifteen of 22 FRPs required a Certificate of Pharmaceutical Product (CPP). Sixteen of 2I ( 76 per cent) indicated that external experts may be used in the review process.

\section{Decision criteria}

For II/25 (44 per cent) of FRPs, the product must have been approved in another jurisdiction as a condition of marketing authorisation. 
Generally, where an FRP indicated that a CPP was required, it also required prior marketing experience. The large majority ( $\mathrm{I}_{3} / \mathrm{I} 8 ; 72$ per cent) of FRPs did not require that clinical data be collected in the target jurisdiction. Twelve of 16 (75 per cent) FRPs did not indicate that the agency recognises European Medicines Agency Article 58 approvals to expedite approval of important new medicines. Eleven of I4 (79 per cent) FRPs acknowledged they might rely on a clinically relevant effect on a surrogate or other intermediate endpoint for an approval.

\section{Post-authorisation and disengagement activities}

Periodic re-approvals were required by $20 / 28$ (7I per cent) FRPs. Relicensure timing might extend to intervals of longer than I year. Postapproval requirements in the form of post-authorisation studies (I $4 /$ I 8 ; 78 per cent) and risk management plans (I 2/I 8; 67 per cent) were often required. Most FRPs (20/26; 77 per cent) had been designed so that the NRA could withdraw the product licence if the expected effects or benefit-risk profiles were not observed in a post-approval re-assessment.

\section{Discussion}

We wanted to understand more fully the characteristics of FRPs used by emerging NRAs. Our study may serve as a starting point for further research and discussions about the use of FRPs in a global regulatory environment. How are emerging NRAs moving to create, implement and use FRPs? Despite growing use of FRPs, no international guidelines or a consensus about basic elements or best practices exists.

We observed many common characteristics (Figure I); however, none of the individual characteristics was unique to FRPs. An FRP seems to require that a society be willing to accept uncertainty about benefits and risks (believing that initial data predict clinical benefit) plus an enabling, transparent regulatory environment wherein the NRA can work closely with the applicant. ${ }^{3, \mathrm{II}}$ Publicly available SOPs or guidance on the submission process is key to transparency. Ninety-one per cent of FRPs indicated that an SOP on how to prepare the submission was available. Making review process guidances available (as indicated by 9I per cent of FRPs) supports the WHO Good Review Practices goals of timeliness, predictability, consistency, transparency, clarity, efficiency and a highquality review. ${ }^{\text {I2 }}$

(C) 2016 Macmillan Publishers Ltd. oI97-5897 Journal of Public Health Policy Vol. 37, 3, 3I5-333 327 
Certain elements of FRPs require faster work by the regulator, even if applied to a standard data set; 54 per cent of FRPs had a review target time of 90 days or less compared with 6 months for an FDA Priority Review and ten months for FDA standard reviews. This commendable target can be supported in several ways. Emerging NRAs may focus resources, determining which products to put through an accelerated Expert Review Panel. ${ }^{\mathrm{I} 3}$ A rapid regulatory review may use a risk-based triage approach (verification or abridged reviews that rely on information from predicate decisions by SRAs), ${ }^{\mathrm{I} 4}$ or have work-sharing arrangements with other agencies or WHO. Such sharing can be an effective way to use others' experiences to inform a local approval. ${ }^{\mathrm{I}} 5$

We did not assess how WHO prequalification (PQ) of a product applied to these FRPs. The WHO PQ programme and its 'collaborative' process, plus work sharing programs have been used to provide information and capacity to support emerging NRAs' regulatory decision making. ${ }^{\mathrm{I}}$

While timeliness is important, agencies must ensure a quality review. The quality of their decisions can be strengthened by advice from stakeholders. Advisory Committees often enlist outside experts. ${ }^{\text {II }}$ Seventy-six per cent of FRPs indicated that external experts may be used as part of the review process. But the use of external experts is not without challenges. While their input provides diverse opinions that help define the uncertainty around a new therapy and add to the robustness of the decision-making process, it may introduce a time consuming step.

Some FRPs empower the regulator with the flexibility to base a decision on clinical data obtained before Phase 3. Many (79 per cent of FRPs) were given the power to base a decision on an intermediate or surrogate endpoint. This is consistent with certain FRPs used by SRAs, plus a general trend towards expediting medicine development, review and access. ${ }^{17}$

A large proportion ( 72 per cent) of FRPs did not require submission of clinical data collected in the target jurisdiction. Less emphasis in FRPs on local data for the initial approval may be counterbalanced by a required post-approval risk management plan in 67 per cent and a commitment to conduct post-authorisation studies ( 78 per cent).

An effective FRP combines expedited pre-authorisation review procedures with robust post-authorisation monitoring. Many emerging NRAs do not have the post-authorisation systems to monitor the product closely, as is often required by SRAs 'accelerated' or 'conditional' approvals, particularly when based on not yet validated surrogates. As pharmacovigilance infrastructure expands in low- and middle-income

328 (C) 2016 Macmillan Publishers Ltd. or97-5897 Journal of Public Health Policy Vol. 37, 3, 3I 5-333 
countries, a practical approach to monitoring, reporting, and feedback on the safety and efficacy of products approved via an FRP will play a critical role in the effectiveness and acceptance of FRPs. ${ }^{\text {I8 }}$

Ultimately, the regulator balances the benefits and harms in its jurisdiction throughout the product's lifespan. Applying a systematic structured approach to the documentation of the benefits and risks can help communicate regulatory decisions, ${ }^{19}$ particularly those of FRPs. FRPs will be most successful if it is possible to collect on-going postauthorisation safety and efficacy data.

Do emerging NRAs have the capacity to address the demands of FRPs? Some have limited staff or access to information to expedite regulatory decisions. Less well-resourced NRAs must rely on reviews and inspections that are part of approvals by an SRA or WHO PQ. Relying on predicate approvals by SRAs can have limitations - awaiting an SRA's regulatory review may delay the emerging NRA's decision. Obtaining the CPPs can also delay submissions. SRAs' benefit-risk assessment, moreover, focuses on circumstances in their jurisdictions' health care systems and institutions. They may differ greatly from those in emerging economies, making the SRA benefit-risk assessment less relevant. The WHO PQ and EU's Article 58 processes both focus on the product's benefit-risk profile with respect to emerging economies.

Using our descriptive results, emerging NRAs could benefit by determining how their FRPs compare with practices used by similarly resourced NRAs (Table I; see also supplementary information). Understanding commonality of process can help aligning FRPs and help explore work-sharing opportunities. Regionally aligned regulatory processes to build and share capacity are stated objectives in many jurisdictions (for example, initiatives by East African Community/ African Medicines Regulatory Harmonisation; Gulf Cooperation Council; Pan American Health Organization - CARICOM initiative; Asia Pacific Economic Cooperation). ${ }^{20}$ As emerging NRAs move towards alignment and regionalisation of decision making, the role of FRPs should be a part of the strategy.

\section{Limitations}

FRPs are not, however, panaceas for expedited access to new products. Their value must be balanced against limitations. We found postauthorisation commitments an integral part of most FRPs. But even

(C) 2016 Macmillan Publishers Ltd. oI97-5897 Journal of Public Health Policy $\quad$ Vol. 37, 3, 315-333 329 
SRAs have been slow to get compliance with such commitments ${ }^{2 \mathrm{I}}$ and it is not clear whether this would be any different in emerging NRAs. FRPs may remain prone to Type I errors-prematurely approving nonefficacious or unsafe products.

Some limitations should be recognised when interpreting our results. We based our assessment on sometimes limited public-domain documentation. Some of the publicly available information required important contextual interpretation. To seek more details and clarifications about FRPs, we plan to continue our interactions with emerging NRAs. How often are FRPs used as an alternative pathway? What facilitates or obstructs their use? Are target timelines being met? Finally, the discussion of accelerated access to medicines must, at some point, address the role of health technology assessment, increasingly complicated for emerging economies. Our study focussed on regulatory aspects of FRPs. Their pharmacoeconomic implications should be the subject of future research.

\section{Conclusions}

This study is a first step in describing common characteristics of FRPs from emerging NRAs. We observed diversity in FRP characteristics within regions, suggesting a role for further engagement with emerging NRAs on the design and implementation of their FRPs. FRPs will have a meaningful role in accelerating access to important new medicines. Sponsors of marketing applications for products that may fulfil unmet, serious public health needs should seek to interact early with the NRA. What is the current state of this dynamic field? Can current requirements be addressed based on agency feedback? With further research and experience, we hope to suggest FRP characteristics that could be successfully implemented by emerging NRAs. Finally, as FRPs are also being discussed in the context of the International Conference of Drug Regulatory Authorities, WHO may wish to consider issuing guiding principles for FRPs. Such guidance might help introduce more FRPs in countries where they are still missing, and establish consistency among existing FRPs.

\section{Acknowledgements}

The authors wish to acknowledge the contributions of colleagues from regulatory agencies, pharmaceutical companies and consultancies who 
reviewed our interpretations of the characteristics of FRPs derived from the public domain.

\section{About the Authors}

Lawrence Liberti, MSc, RPh, RAC is the Executive Director of the Centre for Innovation in Regulatory Science, Ltd, London, UK.

Professor Sir Alasdair Breckenridge, CBE is former Chairman of the Medicines and Health care products Regulatory Agency, UK.

Jarno Hoekman, MSc, PhD, is Assistant Professor in Innovation Studies at Utrecht University and a researcher in the Departments of Pharmaceutical Sciences and Innovation Sciences, Utrecht University.

Hubert Leufkens, PharmD, PhD is Professor, Division of Pharmacoepidemiology and Pharmacotherapy, Faculty of Science, Utrecht Institute for Pharmaceutical Sciences, Utrecht University. He chairs the Dutch Medicines Evaluation Board (MEB).

Murray M. Lumpkin, MD, MSc, formerly of the US Food and Drug Administration, is the Deputy Director for Regulatory Affairs, in the Global Regulatory Systems Initiatives, Bill and Melinda Gates Foundation.

Neil McAuslane, BSc, MSc, PhD is Director of the Center for Innovation in Regulatory Science, London, UK.

Pieter Stolk, PhD, a pharmacist, is affiliated with Utrecht University/ UMCU and Escher, the TI Pharma platform for regulatory innovation.

Kaining Zhi is a graduate student in a doctoral program at Temple University, School of Pharmacy, Philadelphia.

Dr Lembit Rägo, PhD, is Head, Regulation of Medicines \& other Health Technologies, World Health Organization. 


\section{References}

I. World Health Organization. (2OI 5 ) African regulators' meeting looking to expedite approval of vaccines and therapies for Ebola, http://www.who.int/medicines/news/AFR_reg_meet/en/, accessed 6 August 2015 .

2. Duggal, E., Kashyap, P., Singh, R. and Kakar, S. (20I4) Fast track approaches for drug approval across the globe. Asian Pacific Journal of Health Science I(I): 2-I 2 .

3. Liberti, L., Stolk, P., McAuslane, N., Somauroo, A., Breckenridge, A.M. and Leufkens, H. (2015) Adaptive licensing and facilitated regulatory pathways: A survey of stakeholder perceptions. Clinical Pharmacology and Therapeutics 98(5): 477-9.

4. Drugs for Neglected Diseases Initiative. (20I3) DNDi: An innovative approach to R\&D for neglected patients ten years of experience \& lessons learned by DNDi, http://www.dndi.org/ images/stories/pdf_aboutDNDi/DNDiModel/DNDi_Modelpaper_20I3.pdf, accessed 6 August 2015 .

5. The Global Fund. (2010) Global fund quality assurance policy for pharmaceutical products (as amended and restated on I4 December 20IO), http://www.theglobalfund.org/documents/psm/ PSM_QAPharm_Policy_en/, accessed 6 August 2015.

6. Baird, L.G. et al (20I4) Accelerated access to innovative medicines for patients in need. Clinical Pharmacology and Therapeutics 96: 559-7I.

7. World Health Organization. (20I5) Assessment of medicines regulatory systems in sub-Saharan African countries: An overview of findings from 26 assessment reports, http://www.who.int/ medicines/areas/quality_safety/regulation_legislation/assesment/en/, accessed 6 August 2015 .

8. Ratanawijitrasin, S. and Wondemagegnehu, E. (2002) Effective drug regulation: A multicountry study. World Health Organization, http://apps.who.int/medicinedocs/pdf/s230oe/s230oe.pdf, accessed 6 August 2015.

9. Pan-American Health Organization. (2015) System for evaluation of the national regulatory authorities for medicines, http://www.paho.org/hq/index.php?option=com_content\&view=article\&id $=$ I 6 I 5 \&Itemid $=$ I 179 \&lang=en, accessed 6 August 20 I 5 .

Io. US FDA. (20I4) Guidance for industry- expedited programs for serious conditions - drugs and biologics, http://www.fda.gov/downloads/drugs/guidancecomplianceregulatoryinformation/ guidances/ucm35830I.pdf, accessed 6 August 2015.

I I. Liberti, L., McAuslane, N., Patel, P., Breckenridge, A., Eichler, H.-G. and Peterson, R. (20I3) Regulatory review: How do agencies ensure the quality of decision making? Clinical Pharmacology and Therapeutics 94(3): 305-308.

I2. World Health Organization. (2015) Forty-ninth report of the WHO Expert Committee on specifications for pharmaceutical preparations. (WHO technical report series; no. 992), Annex 9 Good review practices: guidelines for national and regional regulatory authorities, http:// www.who.int/medicines/areas/quality_safety/quality_assurance/expert_committee/ WHO_TRS_992_web.pdf?ua=I, accessed 25 August 2015.

I3. Rägo, L., Sillo, H., 't Hoen, E. and Zweygarth, M. (20I4) Regulatory framework for access to safe, effective and quality medicines. Antiviral Therapy i9(Suppl 3): 69-77.

I4. HSA. (2OII) Guidance on medicinal product registration in Singapore, http://www.hsa.gov.sg/ content/dam/HSA/HPRG/Western_Medicine/Overview_Framework_Policies/Guidelines_on_ Drug_Registration/Guidance \% 200n \% 20Medicinal\% 20Product $\%$ 20Registration $\%$ 20in \% 20Singapore\%2020I I \%20(Main\% 20Guidance\%20Document\%20Only).pdf, accessed 6 August 20I5.

I 5. Saidu, Y., De Angelis, D., Aiolli, S., Gonnelli, S. and Georges, A.M. (2013) A review of regulatory mechanisms used by the WHO, EU and US to facilitate access to quality medicinal products in developing countries with constrained regulatory capacities. Therapeutic Innovation and Regulatory Science 47(2): 268-76. 
I6. World Health Organization. (20II) Guideline on submission of documentation for prequalification of multisource (generic) finished pharmaceutical products (FPPs) approved by stringent regulatory authorities (SRAs). PQP0900I/Ver.I, http://apps.who.int/prequal/info_applicants/ Guidelines/PQProcGenericSRA_July20I I.pdf, accessed 6 August 20 I 5.

I7. Shea, M.B., Roberts, S.A., Walrath, J.C., Allen, J.D. and Sigal, E.V. (20I3) Use of multiple endpoints and approval paths depicts a decade of FDA oncology drug approvals. Clinical Cancer Research 19: 3722-3731.

I8. Council for International Organizations of Medical Sciences (CIOMS). (20I4) Practical approaches to risk minimisation for medicinal products: Report of CIOMS Working Group IX. Geneva, Switzerland: Council for International Organizations of Medical Sciences (CIOMS).

I9. Walker, S.R., McAuslane, N., Liberti, L., Leong, J. and Salek, S. (20I 5) A universal framework for the benefit-risk assessment of medicines: Is this the way forward? Therapeutic Innovation and Regulatory Science 49(I): I7-25.

20. Lezotre, P.-L. (20I4) International Cooperation, Convergence and Harmonization of Pharmaceutical Regulations: A Global Perspective. Waltham, MA: Academic Press.

2I. Fain, K., Daubresse, M. and Alexander, G.C. (20I3) The food and drug administration amendments act and postmarketing commitments. The Journal of the American Medical Association 310(2): 202-204.

\section{Supplementary information accompanies this article on the Journal of Public Health Policy Website www.palgrave-journals.com/jphp}

